\title{
Transitions in surgical education
}

\author{
Michael O. Meyers, MD*, Anthony G. Charles, MD, MPH \\ Department of Surgery, The University of North Carolina at Chapel Hill School of Medicine, NC
}

\section{A R T I C L E I N F O}

Article history:

Accepted 30 August 2019

Available online 13 November 2019

\begin{abstract}
A B S T R A C T
There are multiple transitions in surgical education. Among the most significant are those from medical student to intern, from junior resident to senior resident, and from senior resident/fellow to independent practice. While there are new expectations and responsibilities associated with each of these roles, a surgeon's development should be thought of as more of a continuum with distinct points of greatest change and challenge.

There are common themes at these various transitions that may be highlighted for both trainees and
\end{abstract} educators.

\section{Introduction}

Transitions in patient care are often viewed as periods of time that present challenges and potential for pitfalls. Transitions in medical education and training are no different, as students and residents move across the phases of their training, progressing toward independence. These transitions often lead to discontinuity and require both the trainees and the system to respond in order for the trainees to accomplish learning objectives and become independent practitioners. Areas requiring adjustment include, among others, work hours, work environment, new responsibilities, time management, stress and anxiety, fatigue, developing resilience, and learning to integrate education with service. To be successful, managing transitions requires proactivity and a specific set of skills. Transitions can also exacerbate burnout, a risk that extends across the career in many medical disciplines but particularly in surgery. Herein, we seek to explore some of these areas, focusing on a few specific aspects of transition in undergraduate and graduate medical training. While the challenges of some transitions are more substantial than others (transition from student to intern for example), it should be emphasized that transitions are not single events but rather part of a continuum across a career. As these expectations of professional development will be critical to success many years into practice, we should seek to incorporate them in trainees at all levels.

\section{Preparing to pursue a surgical career as a student}

The journey to choosing a specialty, particularly a surgical specialty, varies by individual. Once one has made this decision,

\footnotetext{
* Reprint requests: Michael O. Meyers, MD, 170 Manning Dr., 1150 Physicians Office Bldg., CB \# 7213, Chapel Hill, NC 28599-7213.

E-mail address: michael_meyers@med.unc.edu (M.O. Meyers).
}

what is next? The first step is for a student to find a career goals advisor, particularly one in the specialty of choice, who can help guide the process and set expectations regarding one's level of competitiveness for the chosen surgical specialty. Career goal advisors can help students develop a list of training programs and can give guidance regarding the need to take time for clinical or basic science research to enhance competitiveness. The advisor can help a student in crafting the best schedule for the final year of medical school and in developing a personal statement that strengthens his or her residency application. Specific recommendations for writing a great personal statement are included in Table I.

Next, a student must be strategic in seeking letters of reference. He or she will need at least 3 letters. Faculty members in the specialty of choice, who are familiar with the student, will write the best letters. Therefore, during third-year or fourth-year clinical rotations, students must cultivate relationships with faculty members. Once a candidate letter writer is identified, it is best to ask for feedback before the end of rotation. If the feedback is positive, then one may ask the faculty member if he or she is willing to support the application for residency by writing a strong letter of recommendation. More often than not, the individual will be happy to oblige. It is best not to wait to seek letters until late in the clinical training years. On the rare occasion, a faculty member will hesitate or suggest he or she cannot write a strong letter. A student should see this as an opportunity to seek someone who can write a stronger letter. In addition, most residency programs require a Chair's letter as part of the application. Students should schedule a meeting with the Chair of Surgery and send a curriculum vitae and personal statement, along with United States Medical Licensing Examination scores, to the Chair ahead of time to facilitate a more efficient meeting.

Choosing a residency is one of the most important decisions a student will make in his or her professional life. The breadth of 
Table I

Dos and don'ts of personal statements

Do

Do limit your personal statement to 1 page only with $4-5$ paragraphs.

Do start off by telling the reader who you are and why you want to be a surgeon.

Do describe your attributes that will enable you to excel in your chosen specialty.

Do describe the attributes you are seeking in a residency.

Do describe how you see your career in this field progressing over time.

clinical exposure, the quality of the residents and faculty, and the overall learning environment will play a major part in one's formation as a surgeon. A few things to consider when applying include career goals, geographic location, number of programs, and program specifics. Residency program type should be evaluated and considered as it relates to career interests, particularly when considering between university-based and independent/ community-based programs. One way to determine if a residency program will prepare one for the career of choice is to evaluate which fellowships and careers past residents have achieved. This can help the student infer if the residency program will prepare them for their desired career. There are many paths to one's ultimate career goal. Choosing a residency type that best aligns with future career goals is a good way to jumpstart a career path. For some medical students, geographic location is a paramount factor. Is a program close to a spouse, family member, or a region of the country in which one wishes to live? All of these are important to consider as one evaluates programs, and each student will have to decide how to prioritize these variables.

The number of programs to apply to, application costs, and time demands should be a student's next considerations. This will vary by candidate, but conventional wisdom suggests targeting approximately 25 to 30 residency programs, with the hope of interviewing in at least 12 , depending on variety of programs chosen. If one is seeking highly competitive residency programs, a broader net should be cast. If one is being more selective or feels confident in the program choices, applying to fewer programs may be appropriate. Cost is a factor in the number of program applications as well. In 2018, the application cost was $\$ 99$ for the first 10 residency applications, $\$ 14$ per program for numbers 11 to $20, \$ 18$ per program for 21 to 30 , and $\$ 26$ for each subsequent application. ${ }^{1}$ The student must also budget the cost of travel and accommodation for the interviews. Additionally, residency interviews occur from late October to early January, so students should keep in mind how much time is needed to dedicate and prepare for interviews when applying to programs. Consider organizing rotations around this time period to keep time open and available for interviews. Residency interviews and applicant performance will ultimately determine one's fate. Most students invited for interviews by a program are competitive for that program on paper. Therefore, one must be well prepared on the interview day. Seeking out surgical mentors and performing mock interviews is an important step in getting prepared. One should be familiar and prepared to discuss everything on one's curriculum vitae and should be looking for ways to show one's humanity during the interview process.

\section{Preparing to start residency}

Once matched, the student will be contacted by the program to begin preparing to start residency. Students should utilize resources provided by the program and contact current residents to help with advice about the transition. In addition to logistical details, there are several things for which one should prepare before beginning residency. As this is a time of major change in both professional and personal domains, the student should use both professional and personal resources for support. Common areas to consider include developing organizational skills, working with teams, establishing personal priorities to make decisions for worklife balance, finding and utilizing mentors, defining and remembering one's goals and exploring one's interests, realizing that one will be overwhelmed at times, preparing to accept criticism, and developing resiliency. ${ }^{2}$

It is never too soon to begin reading and developing surgical knowledge. This should begin before starting residency. Students should choose a standard surgical textbook and establish a reading plan prior to beginning of internship. This provides a head start on training and eases the transition of gaining surgical knowledge when one is trying to master many other things as a surgical intern.

\section{Setting expectations for graduate medical education}

There are many adjustments once training begins. From an educational perspective, the onus for his or her own education shifts more to the trainee. While trying to adjust to new work environments, one must balance learning with the responsibility of being relied upon for patient care. Residents work more hours/ week than they did as students, and, therefore, need to adjust expectations about time periods available for study. Finally, residents must find balance between work, study, and personal care.

With regard to education and learning, one of the first major adjustments after starting residency is recognizing the difference in environment between medical school and residency. Trainees move from an environment where the focus is largely on them to one where the focus is primarily on the patient, and their own learning must be done within the context of optimal patient care. Second, time management is a critical aspect of success both as a student and a resident, but the amount of time spent in patient care as a resident leaves less flexibility. Perhaps equally importantly, one has much less control of one's time. Creating organized study schedules prepares a resident to be productive when a small amount of time presents itself. It is also critical that residents be prepared to do more in shorter segments of study time. No longer can they wait for a 4-hour block of time to initiate study. Residents must be prepared to make the most of smaller windows of time and look for the opportunity to find that time throughout the workday.

Residents also must be responsible for their own education and assure they are making progress. Correspondingly, faculty need to understand this and to take time to make sure residents are aware of where they need to improve and what they are doing well. There are data that show faculty do not routinely provide feedback, even though they believe they do this well. ${ }^{3,4}$ There are also data that suggest faculty are much better at pointing out areas for improvement, but much less commonly recognize things that are done well. ${ }^{4,5}$ This can create an environment where residents struggle to gain confidence. 
Table II

ACGME core competencies

ACGME Core Competencies

Patient care

Medical knowledge

Practice-based learning and improvement

Systems-based practice

Professionalism

Interpersonal and communication skills

ACGME, Accreditation Council for Graduate Medical Education.

\section{Assessment and evaluation of trainees}

One important aspect of resident development is assuring that they and the faculty involved in resident education understand how trainees are evaluated. While every training program has specific goals and objectives, along with their own evaluation systems, there are national norms and expectations for resident accomplishment. In guiding residents through training and assuring they meet expected educational goals, the fundamental aspects of assessment fall within the 6 core competencies as defined by the Accreditation Council for Graduate Medical Education (Table II). These were described in 1999 and have been used as the foundation for emphasis on educational outcomes as opposed to processes. While these provided a foundation for specialties to develop instructional and assessment methods in order to integrate competencies into educational curricula, they proved less effective as outcomes measures. The Accreditation Council for Graduate Medical Education developed specialty-specific milestones based on these competencies, which were piloted in 2013 and became fully implemented for all specialties in 2015. These documents are specialty-specific, provide a framework for assessment of resident development in key areas of training, and are designed to evaluate progress across the years of residency. In general surgery, 16 milestones are defined and organized across the 6 competencies. ${ }^{6}$ After initial evaluation and feedback, these have been revised and new milestones will be implemented in July $2020 .^{7}$ There are no mandates regarding milestone achievement or any specific standards that must be achieved for a resident to progress and finish training, but they seek to set a common set of goals across programs and training environments. More recently, Entrustable Professional Activities have been developed in surgery and are currently being piloted by the American Board of Surgery. ${ }^{8}$ These are specialtyspecific goals that are measurable and seek to represent essential activities that would be expected of a practicing physician in ways that other evaluation tools, such as the milestones, are not able to accomplish. ${ }^{8}$ While currently being evaluated in pilot studies, tools such as these may become important criteria used to evaluate trainee development, readiness to enter practice, and, potentially, as requirements for board certification.

\section{Managing stress and burnout}

Increasingly recognized are the issues of physician wellness and burnout. Compared to many other specialties, these issues are magnified in surgical specialties and are of critical importance in both residency and during the transition to independent practice. Surgeons have high rates of burnout and depression. 9,10 Surgical trainees manifest these problems to even greater degrees, with junior residents at greater risk than those more senior. ${ }^{11-13}$ Awareness is the first step in managing these challenges, but moving forward it will be necessary to develop solutions to these issues. Providing support and understanding for trainees during these transitions is an important first step. Many institutions have developed resources to attempt to address burnout, but prevention remains elusive. Recognizing that some people will struggle more than others with the expectations of new roles is a starting point. It is crucial for surgical faculty to be aware and look for signs of burnout, depression, and anxiety. For faculty, training programs, and surgical departments, the next step is creating initiatives to address burnout and teaching skills to help residents navigate these challenges. Such initiatives have become more common among surgical training programs, with some having developed programs going back nearly 10 years. ${ }^{14}$ Efforts at promoting individual skills to develop resilience have been described, as well. While it is early in the era of addressing these issues in surgery, they will be important to focus on during training, as we develop a better understanding of not just the challenges, but what can be done to prevent them.

\section{Individualizing education}

There is a continuum of development across all levels of surgical education, from student to resident to independent practice. Many areas fall under the umbrella of the 6 core competencies, including surgical knowledge, patient care (both in and out of the operating room), professionalism, and interpersonal and communication skills, among others. Other areas fit less cleanly in that rubric but are similarly important, including critical thinking, problem solving, confidence, judgement, leadership, and independence. While any individual may have specific strengths in a single area compared to others, a successful surgeon will reach a benchmark for all these qualities. But it is important to recognize that everyone has their own development curve for these skills, and it is expected that progression from novice to mastery will not be the same for each skill, nor will any learner have the exact same pattern of skill acquisition. As such, it is imperative for surgical educators to learn to recognize individual differences and set expectations based on learner-specific goals. This requires recognizing where an individual trainee stands in their development curve (based on actual assessment, not simply training level) and providing focused and specific feedback. This should be an ongoing conversation while working with a resident, and it is critical to separate this from a summative evaluation after completion of a rotation. For residents, honest self-assessment of strengths and weaknesses becomes an important part of this process. Moreover, residents should be prepared to take charge of their education and have specific conversations with faculty about areas for improvement. They also must be receptive to constructive feedback, even if it feels critical, and recognize this is necessary to optimal improvement. This, of course, requires a learning environment focused on ongoing improvement, not a punitive environment where residents feel like they are constantly being critically evaluated. In large part, it falls on the faculty to create the necessary conducive environment for learning.

\section{Transition to practice}

The transition to independent practice shares many of the other issues outlined above and is a critical (and potentially fragile) time in the career of a surgeon. Experiences during the 1 to 2 years after training can have a lasting impact and may significantly influence long-term success. While they are still trainees, it is critical to prepare graduating residents and fellows for transition into independent practice. Surgical educators must recognize (and remember) the unique challenges during that time in a surgical career, and the potential vulnerability a surgeon faces in those first months and years as an independent practitioner. Experiences encountered during training can widely vary, with some data suggesting residents in independent programs may have more 
confidence in their skills, although they may not have had as broad an exposure to the spectrum of surgical diseases. ${ }^{15}$ Depending on the training environment, this may be the first time an individual may have complete independence in the operating room without someone else present. This can make it difficult for young surgeons to start their careers on sound footing and can lead to issues with confidence. They are often asked to begin practice in settings that are new and may bear little resemblance to those experienced during training. In addition, they will work with new anesthesia teams and nursing staff who may be accustomed to practicing in ways unfamiliar to a new surgeon. The first 2 years in practice truly are "make or break" time, and both new surgeons and their patients are best served by recognizing that this period of significant adjustment requires support, both from those with whom they are working and those who helped train them. Even at a distance, the faculty with whom young surgeons worked during training can support them. This may be as simple as taking a call about a patient, but, more importantly, may require actively checking in on individuals, as they may be reluctant to reach out on their own. One excellent review was recently published about transitions to practice that highlights several of these areas. ${ }^{16}$

In conclusion, multiple transitions occur during surgical training, with emphases on different areas of challenge at different points in training. These span the gamut from personal to professional. There is no single strategy in assuring effective transition from intern to independent practice, but from the very beginning of training, trainees and surgical educators should work towards honest self-evaluation, constructive criticism through immediate and continuous feedback, and personal support with an eye to developing confidence and independence at the completion of training.

\section{Funding/Support}

No funding was received for this work.

\section{Conflicts of interest/Disclosure}

There are no disclosures relevant to either author.

\section{References}

1. Association of American Medical Colleges. Fees for ERAS Residency Applications; 2019. https://students-residents.aamc.org/applying-residency/article/ fees-eras-residency-applications/. Accessed April 12, 2019.

2. Gallaher J, Purcell L. I am a surgery resident now, 10 things I wish I had learned as a medical student. In: Englesbe M, Meyers M, eds. A How To Guide For Medical Students. New York: Springer International Publishing; 2017:155-163.

3. Sender Liberman A, Liberman M, Steinert Y, McLeod P, Meterissian S. Surgery residents and attending surgeons have different perceptions of feedback. Med Teach. 2005;27:470-472.

4. Rose JS, Waibel BH, Schenarts PJ. Disparity between resident and faculty surgeons' perceptions of preoperative preparation, intraoperative teaching, and postoperative feedback. J Surg Educ. 2011;68:459-464.

5. Scarlet S, Reiter A, Crowner J, Meyers MO, eds. Blind spots in the feedback process - exploring trainee and faculty perceptions. Paper presented at: 13 th Annual Academic Surgical Congress; January 30-February 1, 2018; Jacksonville, FL. https://www.asc-abstracts.org/abs2018/39-02-blind-spots-in-thefeedback-process-exploring-trainee-and-faculty-perceptions/. Accessed July 13, 2019.

6. Accreditation Council for Graduate Medical Education. The General Surgery Milestone Project; 2015. https://www.acgme.org/Portals/0/PDFs/Milestones/ SurgeryMilestones.pdf?ver=2015-11-06-120519-653. Accessed July 13, 2019.

7. Accreditation Council for Graduate Medical Education. Surgery Milestones; (2019). https://www.acgme.org/Portals/0/PDFs/Milestones/ SurgeryMilestones2.0.pdf?ver=2019-05-29-124604-347. Accessed July 13, 2019.

8. Brasel KJ, Klingensmith ME, Englander R, et al. Entrustable professional activities in general surgery: development and implementation. J Surg Educ 2019:75:1174-1186.

9. Balch CM, Freischlag JA, Shanafelt TD. Stress and burnout among surgeons: Understanding and managing the syndrome and avoiding the adverse consequences. Arch Surg. 2009;144:371-376.

10. Dimou FM, Eckelbarger D, Riall TS. Surgeon burnout: A systematic review. J Am Coll Surg. 2016;222:1230-1239.

11. Dahlke AR, Quinn CM, Chung JW, Bilimoria KY. Surgical residents' work hours and well-being in year 2 of the FIRST trial. N Engl J Med. 2017;377: 192-194.

12. Bilimoria KY, Chung JW, Hedges LV, et al. National cluster-randomized tria of duty-hour flexibility in surgical training. N Engl J Med. 2016;374: $713-727$.

13. Williford ML, Scarlet S, Meyers MO, et al. Multiple-institution comparison of resident and faculty perceptions of burnout and depression during surgical training. JAMA Surgery. 2018;153:705-711.

14. Salles A, Liebert CA, Esquivel M, Greco RS, Henry R, Mueller C. Perceived value of a program to promote surgical resident well-being. J Surg Educ. 2017; 74: 921-927.

15. Jones J, Sidwell RA. Residency surgical training at an independent academic medical center. Surg Clin North Am. 2016;96:147-153.

16. Cogbill TH, Shapiro SB. Transition from training to surgical practice. Surg Clin North Am. 2016:96:25-33. 